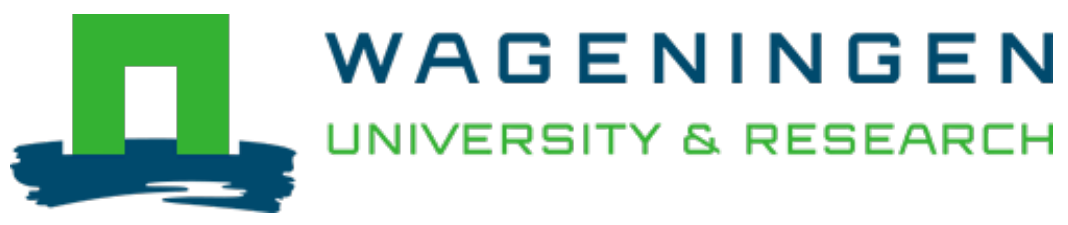

\author{
Transcriptome-based identification of the beneficial role of blackcurrant, \\ strawberry and yellow onion to attenuate the cytopathic effects of Clostridium \\ difficile toxins \\ Journal of Berry Research \\ Venkatasubramanian, P.B.; Oosterink, E.; Tomassen, M.M.M.; Suarez Diez, M.; Mes, J.J. et al \\ https://doi.org/10.3233/JBR-200646
}

This article is made publicly available in the institutional repository of Wageningen University and Research, under the terms of article $25 \mathrm{fa}$ of the Dutch Copyright Act, also known as the Amendment Taverne. This has been done with explicit consent by the author.

Article 25 fa states that the author of a short scientific work funded either wholly or partially by Dutch public funds is entitled to make that work publicly available for no consideration following a reasonable period of time after the work was first published, provided that clear reference is made to the source of the first publication of the work.

This publication is distributed under The Association of Universities in the Netherlands (VSNU) 'Article $25 \mathrm{fa}$ implementation' project. In this project research outputs of researchers employed by Dutch Universities that comply with the legal requirements of Article 25fa of the Dutch Copyright Act are distributed online and free of cost or other barriers in institutional repositories. Research outputs are distributed six months after their first online publication in the original published version and with proper attribution to the source of the original publication.

You are permitted to download and use the publication for personal purposes. All rights remain with the author(s) and / or copyright owner(s) of this work. Any use of the publication or parts of it other than authorised under article $25 \mathrm{fa}$ of the Dutch Copyright act is prohibited. Wageningen University \& Research and the author(s) of this publication shall not be held responsible or liable for any damages resulting from your (re)use of this publication.

For questions regarding the public availability of this article please contact openscience.library@wur.nl 


\title{
Transcriptome-based identification of the beneficial role of blackcurrant, strawberry and yellow onion to attenuate the cytopathic effects of Clostridium difficile toxins
}

\author{
Prashanna Balaji Venkatasubramanian ${ }^{\mathrm{a}, 1}$, Els Oosterink ${ }^{\mathrm{a}}$, Monic M. M. Tomassen ${ }^{\mathrm{a}}$, \\ Maria Suarez-Diez ${ }^{\mathrm{b}}$, Jurriaan J. Mes ${ }^{\mathrm{a}}$, Edoardo Saccenti ${ }^{\mathrm{b}, *}$ and Nicole J. W. de Wit ${ }^{\mathrm{a}, *}$ \\ ${ }^{a}$ Wageningen Food \& Biobased Research, Wageningen University \& Research, Wageningen, the Netherlands \\ ${ }^{\mathrm{b}}$ Laboratory of Systems and Synthetic Biology, Wageningen University \& Research, Wageningen, the Netherlands
}

Received 21 July 2020

Accepted 6 February 2021

Pre-press 05 May 2021

Published 14 June 2021

\begin{abstract}
.
BACKGROUND: Clostridium difficile Infection (CDI) can lead to diarrhea and fulminant colitis. $C$. difficile infects the host using toxins. Recent studies report prevalence of CDI in the small intestine. Berries are known to contain antioxidants and phenolic compounds that might mitigate bacterial infection.

OBJECTIVE: We explored the impact of $C$. difficile toxins on the small intestine using an in vitro approach and used systems biology techniques together with data integration to identify food compounds that can reduce their cytopathic impact.

METHODS: Differentiated Caco-2 cells were exposed to $C$. difficile toxins and the transcriptomic changes were studied. To identify foods with potential beneficial counteracting effects, the transcriptomic profiles were integrated with transcriptomics data from Caco-2 cells exposed to various food compounds and analyzed using multivariate analysis.

RESULTS: Beneficial food candidates, selected by multivariate analysis, such as blackcurrant, strawberry and yellow onion were further examined for their potential to counteract the effect of the toxin-induced disruption of cell integrity and toxin translocation. Our results confirmed effects of food compounds, on the cytopathic effects of toxins in the small intestine.

CONCLUSION: Blackcurrant, strawberry and yellow onion can counteract $C$. difficile toxins induced effects.
\end{abstract}

Keywords: Caco-2, microarray, principal component analysis, Clostridium difficile Toxin A, Clostridium difficile Toxin B

\footnotetext{
${ }^{1}$ Center for Molecular and Biomolecular Informatics, Radboud UMC, Nijmegen, the Netherlands.

*Corresponding authors: Nicole J.W. de Wit, PhD, Wageningen Food \& Biobased Research, Wageningen University \& Research, P.O. Box 17, 6700 AA, Wageningen, The Netherlands, Tel.: +31 317 480310; E-mail: nicole.dewit@ wur.nl and Edoardo Saccenti, PhD, Laboratory of Systems and Synthetic Biology, Wageningen University \& Research, Stippeneng 4, 6708WE, Wageningen, the Netherlands. Tel.: +31317 486948; E-mail: edoardo.saccenti@wur.nl.
} 


\begin{tabular}{ll}
\multicolumn{2}{l}{ Abbreviations } \\
PCA & Principal Component Analysis \\
DE & Differential expression \\
CDI & Clostridium difficile Infection \\
IPA & Ingenuity Pathway Analysis \\
TEER & Trans Epithelial Electrical Resistance \\
ToxA & Clostridium difficile Toxin A \\
ToxB & Clostridium difficile Toxin B \\
DMEM & Dulbecco's Modified Eagle Medium
\end{tabular}

\section{Introduction}

Clostridium difficile infection (CDI) affects hundreds of thousands of people each year and causes a broad spectrum of symptoms that range from watery diarrhoea to fulminant colitis [1-3]. C. difficile spores are able to endure extreme conditions and can colonize the intestine, especially when normal microbiota have been disturbed by the antibiotics $[1,2,4]$. Most $C$. difficile strains produce two major exotoxins, toxin A and toxin B (ToxA and ToxB, also called TcdA and TcdB respectively) through which the infection progresses [4]. ToxA and ToxB share $44 \%$ sequence identity between each other and are found to have overlapping enzymatic function as mono-glucosyltransferases that catalyze the glucosylation and thereby inactivate Rho-GTPases [4]. Many investigations have been conducted to understand the functional mechanisms of the toxins. In 3-D and 2-D intestinal epithelial cell model systems, low doses of ToxA have been found to alter cell polarity by inducing plasma membrane components redistribution [5]. In Caco-2 cells monolayer experiments, ToxA has been found to assist translocation of the toxins more than ToxB alone [6]. On the other hand, the cytotoxicity of ToxB has been found to be $100-10,000$ times more potent than ToxA in several cell types [4]. After intestinal translocation, the exotoxins (ToxA and ToxB) bind to the cell surface receptors followed by the toxins being internalized into host cells of various tissue origin [4]. On internalization, the toxins inactivate the Rho GTPases after which downstream cytopathic and cytotoxic effects in the host cells occur [4]. Minor differences between the mechanisms of the toxins action might be explained by the use of different animal models, different toxin dosages or unidentified genetic variations in $C$. difficile strains [4].

For many years, CDI studies have focused on CDI in large intestine as $C$. difficile was initially thought to solely colonize the large intestine [2,7]. However, recent studies indicate that $C$. difficile also infects the small intestine and the incidence of infections in small intestine is increasing [7-11]. There is also increasing incidence of CDI in patients suffering from Intestinal Bowel Disease (IBD) who have undergone surgical procedures [7-9]. IBD is an intestinal disease known to affect both colon as well as the terminal ends of the small intestine. Additionally, an earlier study indicates the presence of asymptomatic $C$. difficile load in the small intestine in about $3 \%$ of the population $[9,12]$. In the light of these increasing evidences, understanding the impact of $C$. difficile on small intestinal epithelia is of utmost importance. Moreover, finding new therapeutics or preventive strategies for CDI are necessary [13, 14], since infections from antibiotic resistant strains are increasing in recent times [15]. A food-based strategy which can easily be adapted as a lifestyle change could be a way forward. Such a strategy could be used to support medicine based therapeutic treatment, similar to the method applied for treating infection from Helicobacter pylori [16].

This manuscript is the first study on the identification of potential food compounds that can reduce the toxic effects of the $C$. difficile toxins on small intestinal enterocyte using Caco-2 monolayer cultured for 21 days as model system. We have analyzed the transcriptional response of these cells to toxin exposure. Next, we have used an integrative biology approach in analyzing already existing transcriptomics studies involving Caco- 2 cells 
exposed to food in order to select candidate food substances to attenuate the cytopathic effect of the $C$. difficile toxins. Finally, we validated their potential beneficial effects by measuring the counteracting capacities of food against the $C$. difficile toxins induced loss of integrity of Caco-2 cells in vitro (cultured for 21 days to mimic small intestinal epithelia).

\section{Materials and methods}

\subsection{Caco-2 cell culture}

ATCC derived Caco-2 cells (catalogue number ATCC $C^{\circledR} H T B-37^{\mathrm{TM}}$ ) were cultured in Dulbecco's modified Eagle's medium (DMEM; Gibco-Invitrogen, Bleiswijk, The Netherlands) with $4.5 \mathrm{~g} / \mathrm{L}$ glucose, $0.58 \mathrm{~g} / \mathrm{L}$ glutamine, no pyruvate, supplemented with $10 \%$ heat inactivated FBS (Hyclone Perbio, Etten-Leur, The Netherlands) and used with passage numbers between 30 and 40. For transwell assays, 330,000 cells were seeded on ThinCert transwells (Greiner Bio-One, ThinCerts \#662640, $0.4 \mu \mathrm{M}$ translucent) with $33.6 \mathrm{~mm}^{2}$ membranes and $0.4 \mu \mathrm{M}$ pores in 24-well suspension culture plates. Cells were grown for 21 days at $5 \% \mathrm{CO}_{2}$ and $37^{\circ} \mathrm{C}$ and apical $(150 \mu \mathrm{L})$ and basolateral $(700 \mu \mathrm{L})$ medium were replaced three times per week.

\subsection{In vitro digestion}

A total of 15 grams of white onion, yellow onion, blackcurrant (Ben Finlay cultivar) and strawberries (Sabrina cultivar) were mixed with an equal amount of $140 \mathrm{mM} \mathrm{NaCl} / 5 \mathrm{mM} \mathrm{KCl}$ and mashed with an ultra torax. The in vitro digestion protocol was mainly based on the paper of Vreeburg et al. with some slight modifications and in line with the standardized protocol as proposed by Minekus et al. [17, 18]. In more detail, $20 \mathrm{gr}$ of sample were transferred into a $50 \mathrm{~mL}$ tube, the $\mathrm{pH}$ was adjusted to 2 with $\mathrm{HCl}$ and $0.667 \mathrm{~mL}$ of $40 \mathrm{~g} / \mathrm{L}$ porcine pepsin in $0.1 \mathrm{M}$ $\mathrm{HCl}$ was added. The samples were then incubated for $30 \mathrm{~min}$ at $37^{\circ} \mathrm{C}$. Subsequently, $1 \mathrm{M} \mathrm{NaHCO}_{3}$ was added to raise the $\mathrm{pH}$ to at least 5.8 , followed by $0.95 \mathrm{~mL}$ of $4 \mathrm{~g} / \mathrm{L}$ porcine pancreatin in $0.1 \mathrm{M} \mathrm{NaHCO}_{3}$ and $0.5 \mathrm{~mL}$ of a mixture of sodium taurocholate and sodium glycodeoxycholate $\left(176 \mathrm{mM}\right.$ of each) in $0.1 \mathrm{M} \mathrm{NaHCO}_{3}$. The $\mathrm{pH}$ of the sample was adjusted to 6.5 with $1 \mathrm{M} \mathrm{NaHCO}_{3}$, flushed with nitrogen and the sample was subsequently incubated for $60 \mathrm{~min}$ at $37^{\circ} \mathrm{C}$. After this incubation the $\mathrm{pH}$ of the sample was adjusted to 7.5 with $1 \mathrm{M} \mathrm{NaHCO}_{3}$ and the weight of the sample was adjusted to $30 \mathrm{~g}$ with $140 \mathrm{mM} \mathrm{NaCl} / 5 \mathrm{mM} \mathrm{KCl}$. Samples were centrifuged for $45 \mathrm{~min}$ at $3023 \times \mathrm{g}$ at $4^{\circ} \mathrm{C}$. The supernatant was taken, flushed with nitrogen and stored at $-80^{\circ} \mathrm{C}$ until further use. For preparing the in vitro digestion control, $140 \mathrm{mM} \mathrm{NaCl} / 5 \mathrm{mM} \mathrm{KCl}$ was used to replace food compounds.

\subsection{Exposure of differentiated Caco-2 cells to toxins and various food compounds}

All C. difficile toxins were derived from List Biological Laboratories, Inc. (Campbell, California, USA; Toxin A (\#152), Toxin B (\#155), Toxin A Toxoid (\#153), Toxin B Toxoid (\#154)). Toxin A and B toxoids, meaning formaldehyde inactivated toxins, were included in the exposure experiments as a control for the cytotoxic effects of the $C$. difficile toxins. For toxin and toxoid incubations, stock solutions of toxins/toxoids $(10 \mathrm{mg} / \mathrm{ml})$ were diluted 40,000 times in DMEM/FBS. 21 day differentiated Caco- 2 cells were exposed on the apical side (final volume $150 \mu \mathrm{l}$ ) to $0.25 \mu \mathrm{g} / \mathrm{ml}$ toxin A (ToxA) or $0.25 \mu \mathrm{g} / \mathrm{ml}$ toxin B (ToxB) or $0.25 \mu \mathrm{g} / \mathrm{ml}$ toxin $A+0.25 \mu \mathrm{g} / \mathrm{ml}$ toxin $\mathrm{B}$ (ToxAB). Optimal exposure concentrations for the toxins were assessed by performing concentrationdependent Caco-2 experiments. One day before the exposure experiments, medium was refreshed and at the day of exposure, medium was removed from the apical and basolateral compartments and toxin or toxoid samples were added to the apical compartment while fresh DMEM/FBS medium was added to the basolateral compartment. To monitor the integrity of the Caco-2 monolayer, transepithelial electrical resistance (TEER) was measured at $37^{\circ} \mathrm{C}$ using a MilliCell-ERS $\Omega$ meter (Millipore, Molsheim, France). In following experiments, Caco- 2 cells 
were co-incubated with $C$. difficile toxins $(0.25 \mu \mathrm{g} / \mathrm{ml}$ toxin A or $0.25 \mu \mathrm{g} / \mathrm{ml}$ toxin B or $0.25 \mu \mathrm{g} / \mathrm{ml}$ toxin $A+0.25 \mu \mathrm{g} / \mathrm{ml}$ toxin B) and various (digested) food compounds, all in a total volume of $150 \mu \mathrm{l}$ in the apical compartment. Therefore, digested white onion (WOd), yellow onion (YOd), blackcurrant Ben Finlay, Strawberry Sabrina and digestion control samples (control digest) were diluted 1:4 in DMEM/FBS medium. Undigested galacto-oligosaccharides (GOS; Friesland Campina, Amersfoort, the Netherlands) were added to the Caco-2 cells in a concentration of $0.5 \mathrm{mg} / \mathrm{ml}$ and DMEM/FBS medium was used as control for this exposure. Also, optimal concentrations of digested and undigested food compounds were assessed by performing concentrationdependent Caco-2 experiments. One day before the exposure experiments, medium was refreshed and at the day of exposure, medium was removed from the apical and basolateral compartments and diluted samples (toxins+food compounds) were added to the apical compartment while fresh DMEM/FBS medium was added to the basolateral compartment. TEER was determined before and at 0,1,3, 4, 5, 6 and $24 \mathrm{~h}$ after addition of samples to check integrity of the intestinal monolayer. In order to be able to reverse the toxic effect of $C$. difficile toxins by food compounds, we focused on a $\sim 35 \%$ drop in TEER after exposure to toxins, since a TEER drop below 35\% seems to damage the cells irreversibly. At that moment ( $\sim 35 \%$ drop in TEER by one of the toxin treatments), the Caco- 2 cells were lysed with $300 \mu \mathrm{L}$ TRIzol (Invitrogen, Life Technologies, Bleiswijk, Netherlands) and the triplicates in each experiment were pooled. After $24 \mathrm{~h}$ incubation, the translocation of toxins to the basolateral compartment was measured using the Clostridium difficile toxin A or B ELISA kit (Catalog No. ABIN1098189, Antibodies-online $\mathrm{GmbH}$, Aachen, Germany). In each experiment, the digested food and control samples were exposed to Caco-2 cells in triplicate and three independent exposure experiments were performed on different days.

\subsection{RNA isolation}

Total RNA was extracted using the QIAshredder and purified RNeasy Mini kits (Qiagen, Venlo, The Netherlands) following the manufacturers' protocols [17]. Briefly, the pooled Caco-2 cell lysates (experimental triplicates) were treated with DNase-I (Sigma-Aldrich, Zwijndrecht, the Netherlands), followed by RNeasy clean-up (Qiagen, Venlo, The Netherlands). Quality and amount of RNA was evaluated by UV spectrometry (260 and $280 \mathrm{~nm}$ wavelength) on the Nanodrop spectrophotometer (Thermo Scientific, Wilmington, DE, USA). To ensure quality of extracted RNA, only samples with RIN number $>8$ were used for microarray analysis.

\subsection{Microarray experiments}

RNAs of each independent Caco-2 experiment with toxin exposures $(n=3$ per treatment) were hybridized to Affymetrix@Human Gene 1.1 ST according to standard Affymetrix@protocols. Quality control of the datasets was performed using Bioconductor packages [19, 20] integrated in an on-line pipeline [20]. Microarray data have been submitted to GEO and can be found under accession code GSE100541.

\subsection{Data preprocessing, differential expression and pathway analysis}

Array data were normalized using the Robust Multiarray Average (RMA) M-estimator method [21, 22], probe sets were defined according to Dai et al. [23]. To exclude interference of non-expressed or very lowly expressed genes, Universal exPression Code (UPC) [24] was computed. Genes with UPC value lower than 0.5 in all replicates were considered to be non-expressed and removed from further analysis. To identify differential gene expression induced by the toxins, pair-wise comparison analyses were performed (toxins versus DMEM control) and genes with $p$-value $<0.01$ were considered to be differentially expressed. Pathway enrichment analysis was performed using Ingenuity Pathway Analysis (IPA) (Ingenuity@Systems, www.ingenuity.com). Significance values for enrichment were calculated using Fisher's exact test (right-tailed). 


\subsection{Data compendium}

Data compendium comprised of microarray data collected from previous food exposure studies reported in Venkatasubramanian et al. [25]. The dataset was restricted to experiments where the exposure was food and food related substances like white and yellow onion, sulforaphane (present in broccoli) and probiotics like L. casei and $B$. breve [25]. Experiments involving mutation inducing agents were avoided. In total, 73 experiments conducted over 15 batches were included in the data compendium and most experiments had been performed in triplicates. Supplementary Data 1 describes the dataset used in the data compendium and their GEO accession number. The data was RMA normalized in batches of experiments using affy and Oligo packages [26, 27] of Bioconductor [19] in R (version 2.3.2) and the differential expression values were calculated using Limma package [28, 29].

\subsection{Principal component analysis}

Principal Component Analysis (PCA) is a statistical technique which is used to reduce dimensionality while conserving significantly large variability in the data [30, 31]. This is achieved by identifying new variables (principal components) that are linear combinations of the original variables. Principal components are orthogonal and each component capture decreasing amounts of information. Basically, PCA results in the projection of the original data on a lower dimensional space (PCA space): observation that are closer to each one in the PCA space are expected to show similar characteristics, in this case gene expression levels. Based on this, PCA was used to select beneficial compounds, under the rationale that foods most distant from toxins would be the most efficient in counteracting the effects of toxins and thus prove to be beneficial against $C$. difficile toxin-induced disruption of intestinal integrity. Meanwhile, it was expected that food compounds closer to toxoids in the PCA space have least beneficial effects.

PCA was performed using the differential expression values of selected genes (e.g. genes from Sumoylation pathway, as derived from IPA or top n-number of regulated genes) from the compendium along with the differential expression values for toxins and toxoids and plots were generated (Fig. 4). PCA was performed in R using 'prcomp' (R version 3.2.3). Data dimensionality was assessed using a Tracy-Widom test at a 0.01 confidence level $[32,33]$. The optimal number of components was 11 for PCA with sumoylation genes and 17 for PCA with top 50 genes. In all cases the selected number of components accounted for $>99 \%$ of variance explained. For visualization purposes only the first two components are shown in Fig. 4.

\subsection{Other statistical analysis}

TEER measurements and Toxin translocation measurements were conducted in biological triplicates. The data was visualized as mean+/- standard deviation and was tested for significant differences between control and treatment using analysis of variance (ANOVA). All $p$-values were corrected for multiple testing using Benjamini Hochberg method.

\section{Results}

\subsection{Gene expression profiling of Caco-2 cells exposed to C. difficile toxins}

Caco-2 cells, differentiated for 21 days into a small intestinal phenotype, were exposed to $C$. difficile ToxA, ToxB, ToxA and ToxB together (ToxAB). The cells were also exposed to the formaldehyde inactivated toxins, toxoids A and B. Transepithelial electrical resistance (TEER) was used to quantify the integrity of the Caco-2 monolayers. On average in the triplicate experiments, after $4.1 \mathrm{~h}( \pm 0.6 \mathrm{~h})$ incubation, a $\sim 35 \%$ drop in TEER (from $\sim 1150 \Omega / \mathrm{cm}^{2}\left( \pm 60 \Omega / \mathrm{cm}^{2}\right)$ to $\sim 700 \Omega / \mathrm{cm}^{2}\left( \pm 105 \Omega / \mathrm{cm}^{2}\right)$ ) was reached on exposure to ToxA and/or ToxAB and RNA of Caco- 2 cells was harvested for microarray analyses. Within this time frame, neither ToxB 


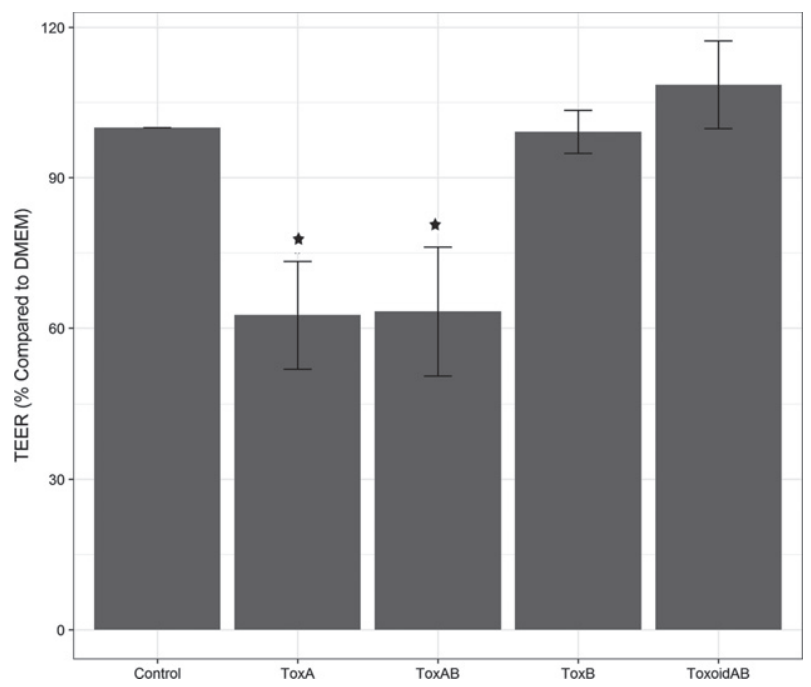

Fig. 1. TEER measured after exposure of Caco-2 cells to ToxA, ToxA and ToxB (ToxAB), ToxB and ToxoidAB compared to DMEM control which was set to $100 \%$. '* ' indicates statistically significant results. A $35 \%$ drop in TEER (from $\sim 1150 \Omega / \mathrm{cm}^{2}\left( \pm 60 \Omega / \mathrm{cm}^{2}\right)$ to $\left.\sim 700 \Omega / \mathrm{cm}^{2}\left( \pm 105 \Omega / \mathrm{cm}^{2}\right)\right)$ was reached on exposure to ToxA and/or ToxAB.

nor the toxoids induced a drop in TEER and did not affect the monolayer integrity (Fig. 1). Differential gene expression was assessed by comparing the $C$. difficile toxin treatments against the DMEM control. To select the genes that are most likely involved in the (cyto)toxic effects of the toxins, we excluded genes that were also differentially expressed by the toxoids compared to DMEM control ( $n=562$ genes). This resulted in the differential expression of 1407 genes for ToxA, 215 genes for ToxB and 1013 genes for ToxAB. Figure 2a shows the top 10 up and down regulated genes for each toxin treatment, based on fold change (FC) $(p$-value $<0.01)$, and combined in a heatmap. For the upregulated genes there is large overlap between the ToxA and ToxAB, but ToxB commonly induced lower FC than ToxA and ToxAB (Figs. 2b and 2c). The most upregulated gene for all toxins was RHOB (Ras homolog gene family, member B), which is a member of the Rho GTP-binding protein family. Among the downregulated genes there seemed to be more variation between the toxins. For ToxA and ToxB individually, ANKRD1 (Ankyrin Repeat Domain 1) was the most downregulated gene, whereas for the combination of toxin A and B (ToxAB), CCL15 (Chemokine (C-C motif) ligand 15) showed the strongest downregulation (Fig. 2a).

Next, differentially expressed genes $(p$-value $<0.01)$ were selected for pathway enrichment analysis. The (canonical) pathways were ranked based on significance of the enrichment score and the top 20 pathways for all toxins are presented in Fig. 3a. The sumoylation pathway showed highest significance in all three perturbations (ToxA, ToxB, ToxAB) and therefore we considered it as an important pathway in Caco-2 cells in response to C. difficile toxin exposure. Sumoylation is a posttranslational modification and has a role in various cellular processes, such as stress and injury $[34,35]$. Figure $3 b$ shows the gene expression changes in the sumoylation pathway induced by ToxAB in detail. Among the genes from this pathway that were differentially expressed, it was found that the Rho GTP-binding protein family genes were substantially affected by the toxins. As $C$. difficile toxins are known to affect Rho GTPases this is not surprising [36, 37]. Additionally, p53 signalling (apoptosisrelated), cell junction and tight junction signalling pathways were observed to be significantly affected. Literature indicates that these pathways might be linked to the drop in TEER and thus the monolayer integrity [38, 39] that we found in our exposure experiments. Pathways related to cytokine signaling like, Interleukin - 8 (IL-8) signaling and integrin-linked kinase (ILK) signaling are other interesting signaling pathways that are activated, indicating a potential effect of toxins on immune-related responses. 


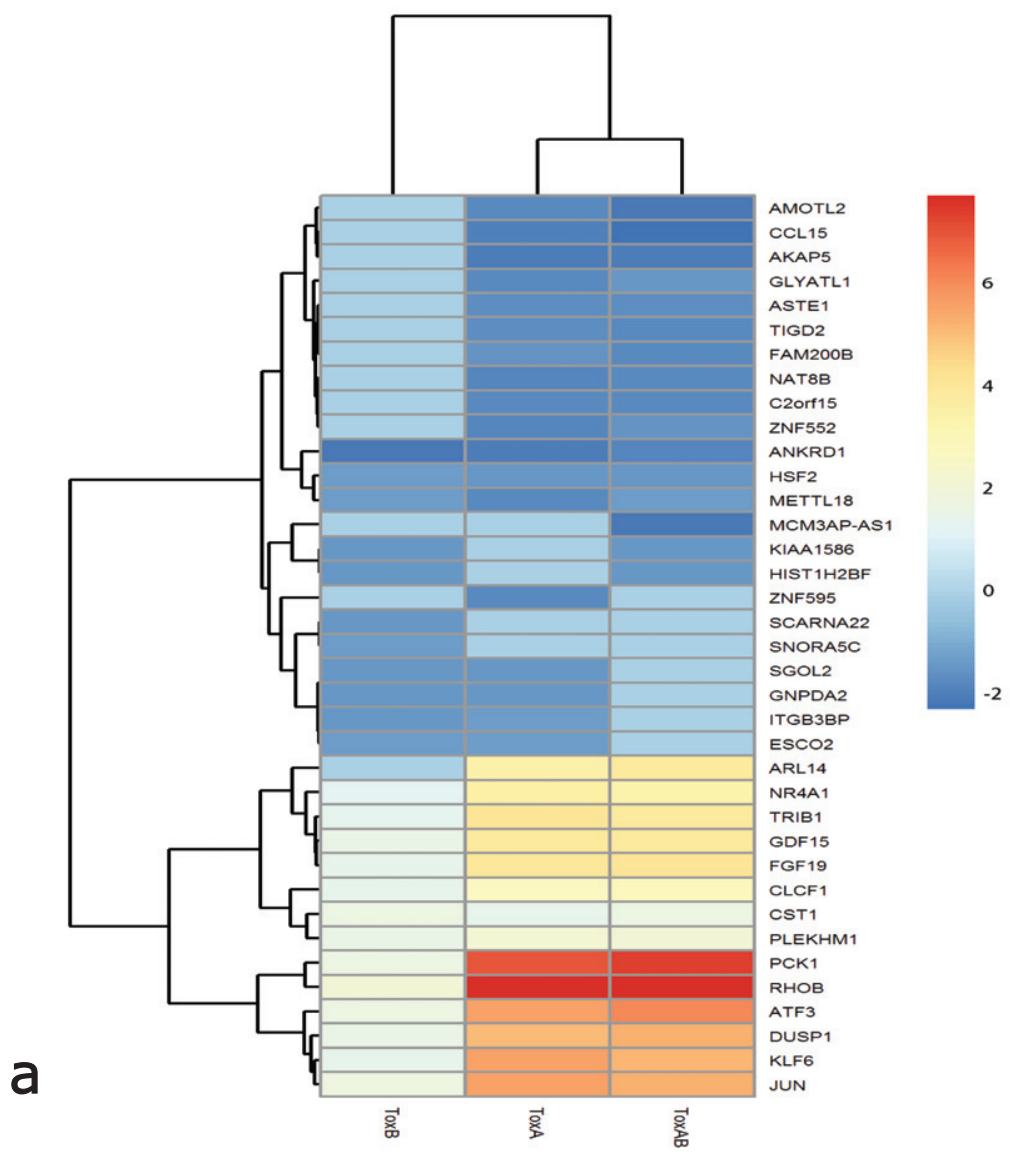

b

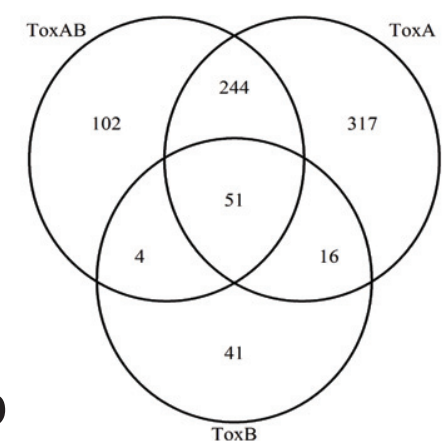

C

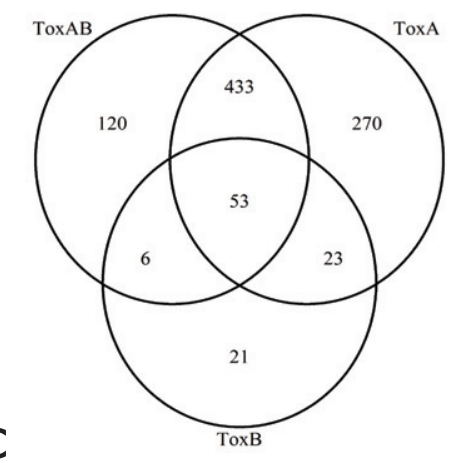

Fig. 2. Heatmap of top 10 up and 10 down regulated genes from experiments where Caco- 2 cells were exposed to ToxA, ToxB and ToxAB (ToxA+ToxB) $(p$-value $<0.01)$, combined for all three toxin exposures. $\mathrm{b} \& \mathrm{c}$ ) Differential expressed genes induced by ToxA, ToxB and ToxAB b) down regulated, c) up regulated.

\subsection{Identification of candidate food compounds with beneficial effects on C. difficile toxin-induced disruption of intestinal integrity}

Principal Component Analysis (PCA) was used to find patterns and identify candidate food compounds with remedial effects for $C$. difficile infection. Only the genes differentially expressed in Caco-2 cells exposed to ToxA and ToxB combined (so ToxAB) were used in this PCA strategy since in vivo mechanisms of action of CDI involve both ToxA and ToxB affecting simultaneously [40]. We combined the data obtained in this study with a compendium of Caco-2 specific gene expression data [25]. The dataset compendium contains differential gene expression data from food exposure studies performed in our lab and from public repositories. The compendium contains 73 experiments performed over 15 batches. The compendium was used together with the expression data from $C$. difficile toxins and toxoid studies here presented, to analyze similarities and/or contradictions between gene expression patterns that might be indicative for a remedial effect of food compounds on CDI.

In first instance, all differentially expressed genes induced by ToxAB and belonging to sumoylation pathway (17 genes) (Fig. 3b), were used to find beneficial food substances using PCA. Sumoylation pathway was chosen 

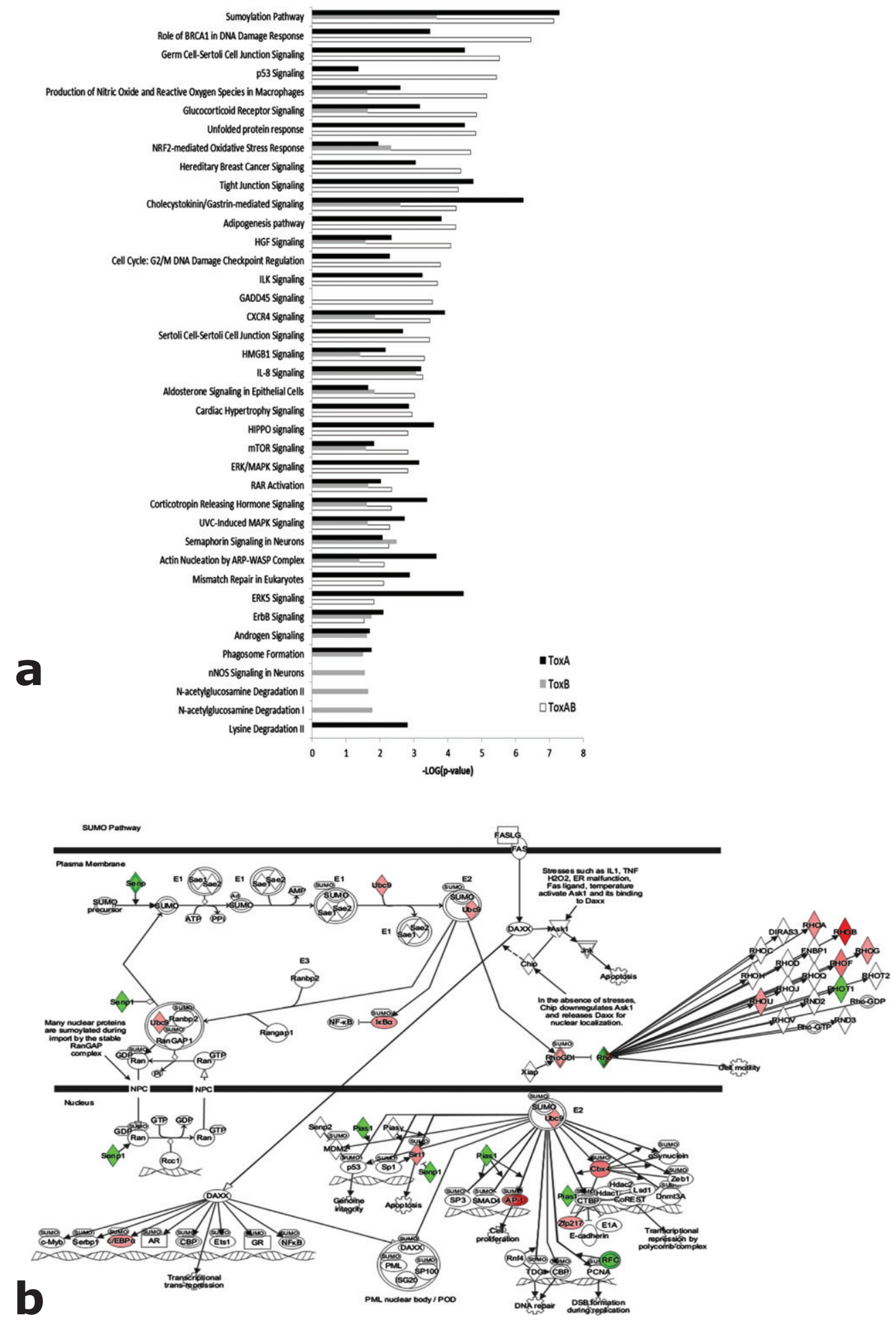

Fig. 3. (Continued) 
Fig. 3. a) Pathways enriched in Caco-2 based on differentially expressed genes induced by ToxA, ToxB and ToxAB. Pathways have been ordered according to $p$-values of enrichment analysis. Only top 20 pathways are shown (combined for all three toxin exposures). b) Differentially expressed genes by ToxAB in Sumoylation pathway as represented by IPA are shown. Red indicates up regulated genes and green indicate down regulated genes. Darker shades indicate larger fold changes.

since this pathway was found to be the most significantly enriched among the pathways enriched in Caco-2 cells upon exposure to the $C$. difficile toxins.

The first two principal components (PCs) are shown in Fig. 4a. The two PCs account for $70 \%$ of the total variance in the data and the first 11 PCs explain $99 \%$ of the variability. In Fig. 4a, we observe that ToxA and ToxAB are distinctly separated from toxoids based on sumoylation pathway genes. On the contrary, ToxB, which also showed less effect on Caco-2 cell integrity than ToxA and ToxAB, was in proximity to the toxoids in the PCA space. We hypothesize that food compounds closer to toxoids in the PCA space would probably have no or less beneficial effects while foods most distant from toxoids and toxins would be most efficient in counteracting the effects of toxins and thus prove to be beneficial for $C$. difficile toxin-induced disruption of intestinal integrity. Based on this hypothesis, blackcurrant (Ben Finlay) might potentially be the most counteracting and fibers (like GOS) least effective against toxin effects or at least against the sumoylation pathway activation. Compounds that are found to be in between toxoids and the toxins (ToxA and ToxAB), such as Strawberry (Sabrina) and yellow onion, might be moderately effective against the toxin induced TEER drop. White onion, which is found closer to the toxoids, is expected to be less effective in attenuating $C$. difficile cytotoxicity.

PCA was also performed using top 25 up and top 25 down regulated genes induced by ToxAB in Caco- 2 cells (Fig. 4b). Differential expression values for 28 of the 50 genes ( 22 genes were not found in all 82 experiments) from other exposure experiments were obtained from the data compendium and used for PCA. In this case, the first two PCs explain $69 \%$ of the total variability (Fig. 4b). 99\% of total variability in the data was explained by 17 PCs. Inspection of this PCA plot (Fig. 4b) shows similar results as the analysis of the PCA plot based on genes within the sumoylation pathway (Fig. 4a), thus reinforcing our hypothesis.

In addition to using sumoylation and top 50 up/down regulated genes, PCA was also performed using the full 1013 genes that were differentially expressed by ToxAB (Supplementary Figure 1). However, here two principal components did not show a clear separation of toxins, toxoids and other food compounds which could lead to predictions of beneficial food substances. In this case, the two first PCs explain 58\% of the variance. The lack of clear separation can be due to the noise induced by the large selection of genes. Many of them may represent a general response to stress conditions and as such they provide no specific response to the tested toxins.

\subsection{Validation of beneficial effects by candidate food compounds on C. difficile toxin-induced intestinal integrity}

Food compounds that were expected to be the most effective, moderately effective and least effective against the toxin-induced cytotoxicity based on PCA, were chosen for experimental verification. These were blackcurrant (Ben Finlay cultivar, most effective), strawberry (Sabrina cultivar, moderately effective), yellow onion (moderately effective), white onion and GOS (least effective). These food substances were verified for their beneficial effects by co-exposing Caco-2 cells to the food substances and the $C$. difficile toxins.

The TEER values which represent the intestinal integrity of the Caco-2 monolayer are shown in Fig. 5. TEER values at the start of the incubation $(t=0)$ was on average $1201 \Omega / \mathrm{cm}^{2}\left(+/-125 \Omega / \mathrm{cm}^{2}\right)$. The TEER values show that blackcurrant mostly diminished the drastic drop in TEER after 24 hours exposure to the toxins. Assuming that the TEER value of DMEM exposed Caco-2 cells (control) is 100\%, then ToxA and ToxAB induced a TEER drop of $69 \%$ and $74 \%$ respectively, after 24 hours of exposure. However, in the presence of blackcurrant, a drop of only $19 \%$ and $16 \%$ of control TEER values was observed to be induced by ToxA and ToxAB respectively (Fig. 5). This was a significant counteractive effect of blackcurrant on toxin-disrupted TEER (adjusted $p$-value $=0.00617$, after 24 hours exposure of ToxAB). Next to this significant reduction in TEER after 24 hours exposure, blackcurrant also induced a substantial delay in TEER drop after 4, 5 and 6 hours of toxin exposure, even for ToxB. 

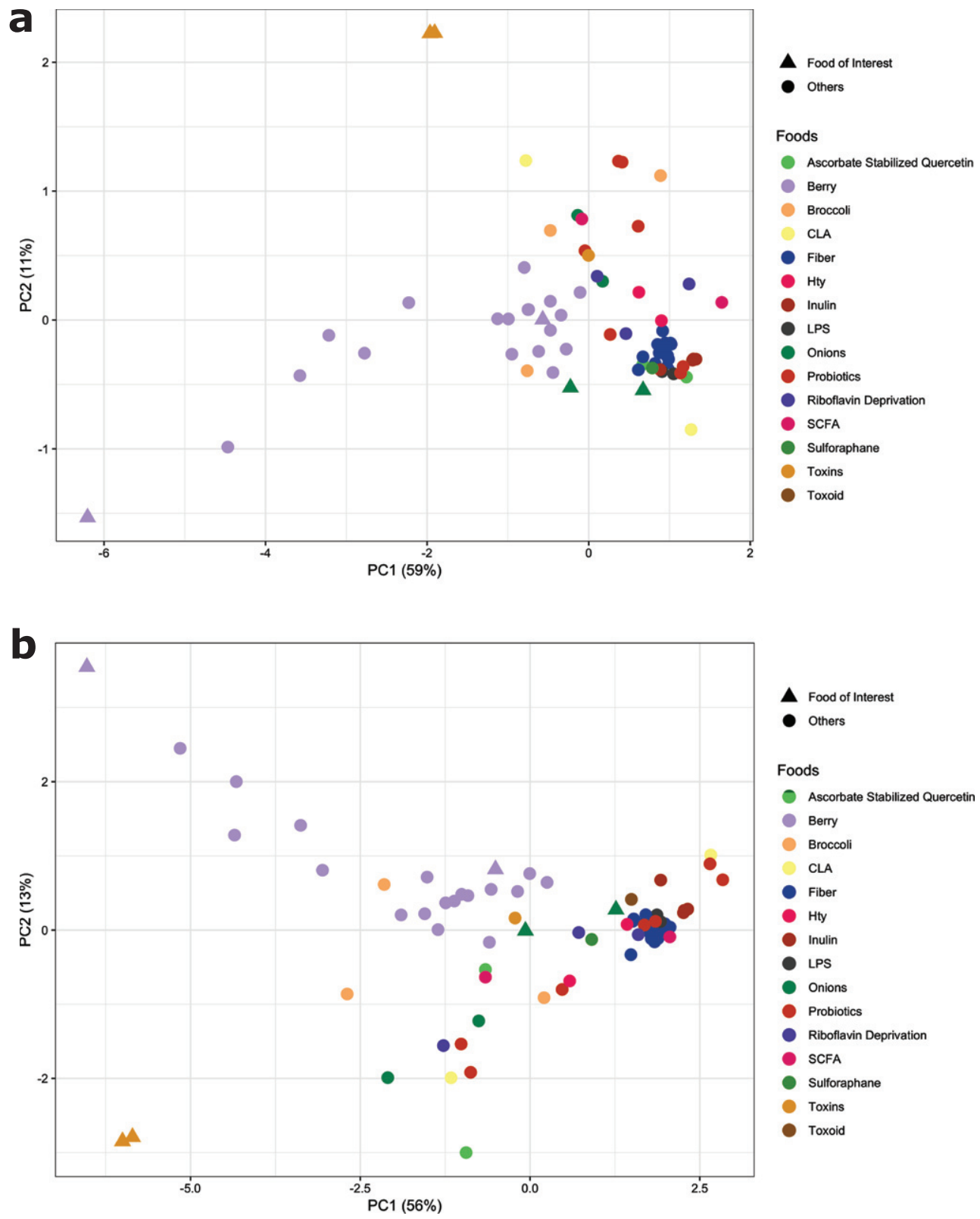

Fig. 4. PCA plots based on a compendium of 15 batches of microarray data collected from 73 food related interventions on Caco- 2 a) 17 genes in the sumoylation pathway were included in PCA b) Top 25 up and top 25 down regulated genes were considered for PCA while only 28 genes were used in PCA as not all 50 genes had differential expression values in all experiments in the compendium.

Strawberry and yellow onion especially delayed the drop in TEER measurements induced by the ToxA and ToxAB, as at time point 6 hours after exposure, significant differences in TEER measures (adjusted $p$ value $=0.0191 \& 0.00830$ for ToxA and ToxAB respectively for strawberries and adjusted $p$-value $=0.0218 \&$ 0.072 for ToxA and ToxAB respectively for Yellow Onion) could be detected. After 24 hours of exposure, the 


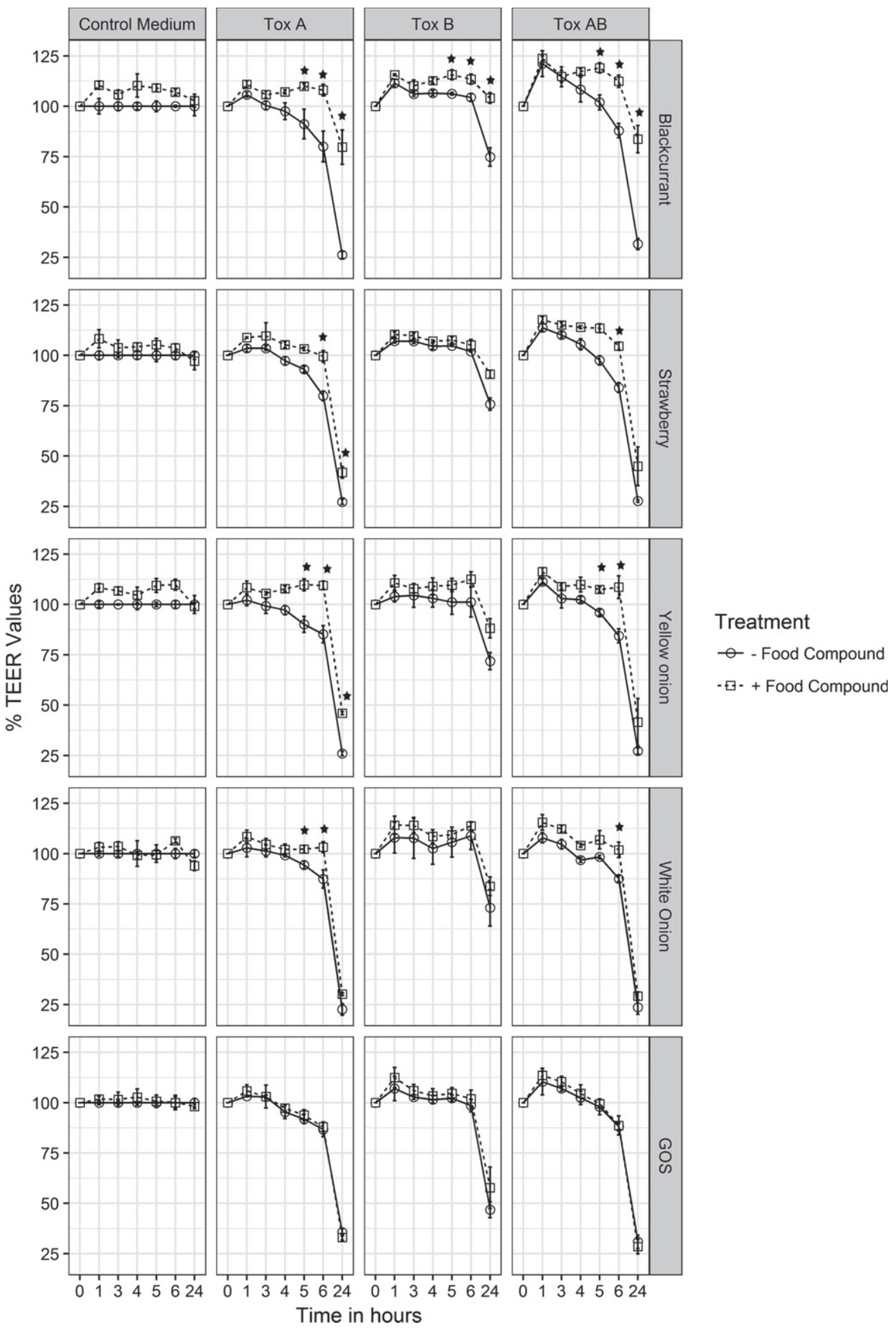

Fig. 5. (Continued) 
Fig. 5. Relative TEER values measured before and after exposure of food compounds along with Toxin exposures (TEER values of control medium w/o food compounds were set to 100\%). Toxins used include ToxA, ToxB and ToxA+ToxB together. Food compounds used are blackcurrant (Ben Finlay), strawberry (Sabrina), yellow Onion, white Onion and GOS. '*' indicates significant differences in TEER values between - and+food compounds. TEER values at the start of the incubation $(t=0)$ was on average $1201 \mathrm{Ohm} / \mathrm{cm}^{2}\left(+/-125 \mathrm{Ohm} / \mathrm{cm}^{2}\right)$.

effects of strawberry and yellow onion were less strong than what was seen for blackcurrant, but still a significant beneficial effect was found for strawberry (but not yellow onion). It can be seen that this counteracting effect was weaker than that induced by blackcurrant. White onion still showed some significant beneficial effect on TEER measures (but less strong than strawberry and yellow onion), whereas GOS showed no significant effect on the $C$. difficile toxin-induced reduction in TEER measures (Fig. 5).

Cytotoxicity by $C$. difficile toxins also includes translocation of the toxins over the intestinal barrier. As an additional confirmatory test for our PCA-based hypothesis, toxin translocation towards the basolateral compartment was studied by ELISA after 24 hours incubation. The results obtained support the TEER measurements (Fig. 6) as blackcurrant abolished the toxin translocation almost completely (adjusted $p$-value $=0.000087$, for ToxA translocation and adjusted $p$-value $=0.00031$, for ToxB translocation, both in case of ToxAB addition). Strawberry and yellow onion showed a moderate preventive effect (adjusted $p$-value $<0.01$ ) on toxin translocation, while white onion showed significant but weaker effect compared to yellow onion and GOS did not have any significant effect on the translocation of ToxA and ToxB. Together these data indicate that blackcurrant, strawberry and yellow onion, and to a lesser extent white onion, may have a protective effect against the disruption of intestinal integrity induced by $C$. difficile toxins.

Sorting the food compounds on their counteractive effectiveness based on TEER values and toxin translocation, in the order of most effective to least effective, coincides with our PCA-based hypothesis. Thus, the efficiency of blackcurrant was found to be the strongest in counteracting toxin-induced cytotoxicity, while strawberry and yellow onion were moderately effective and white onion and GOS were least effective.

\section{Discussion}

A sizeable number of studies in the past have focused on the effects of $C$. difficile and its toxins on large intestine and cecum, with studies involving physiological and gene expression changes [41-46]. However, recently, evidence is emerging on the effects of C. difficile on human small intestine and recurring CDI in hospitals [10]. To the best of our knowledge, our work is the first study focusing on the effects of toxins on transcriptional changes of the small intestine-like enterocytes based on the 21 days Caco- 2 model system. Previous transcriptomics studies have been conducted on the effects of the toxins on cecal models, namely HCT-8 cells (human ileocecal cell lines) and mouse cecal cells $[45,46]$. Among the top upregulated genes we identified are RHOB, JUN, DUSP1, KLF6, GDF15 which were also found to be upregulated in toxin exposure studies involving mice cecum and HCT-8 cells [46-48]. This indicates that these are commonly activated genes by the $C$. difficile toxins. Among the top downregulated genes, ANKRD1 seems to be involved in apoptosis, whereas CCL15 belongs to the CC chemokine family and is a chemoattractant for neutrophils, monocytes, and lymphocytes [49, 50].

Overall, we found that gene expression is largely altered upon exposure to ToxA or ToxAB, whereas relatively smaller change was observed for ToxB. ToxB elicited differential expression of less than one third of the total number of genes differentially expressed by either ToxA or ToxAB. Similarly, TEER measurements indicate that ToxB by itself has less impact on cellular monolayers, at least during the considered exposure time frame. Our results support the assumption that ToxA and ToxB have a synergistic effect in C. difficile infection, where ToxB can cause more harm after reaching the basolateral side of an intestinal cell which it does not reach on its own but for which ToxA paves the way [6].

At pathway level, sumoylation pathway processes seem to be significantly perturbed on all three exposures (ToxA, ToxB, ToxA+ToxB). SUMO (small ubiquitin-like modifier) are a family of small proteins having 


\section{Blackcurrant (Ben Finlay)}

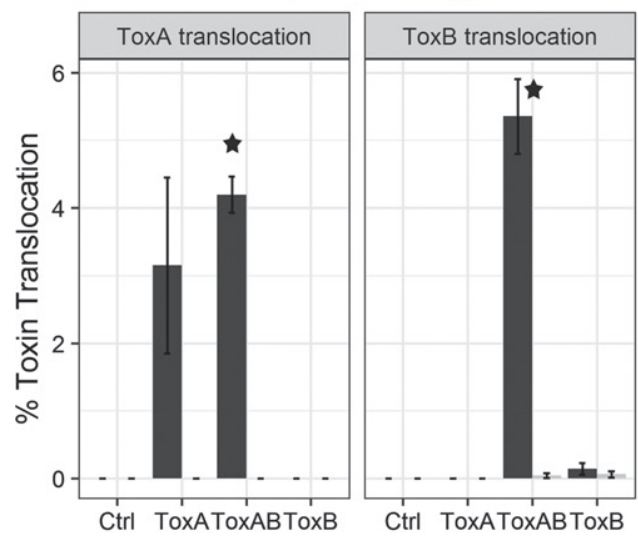

\section{Strawberry (Sabrina)}
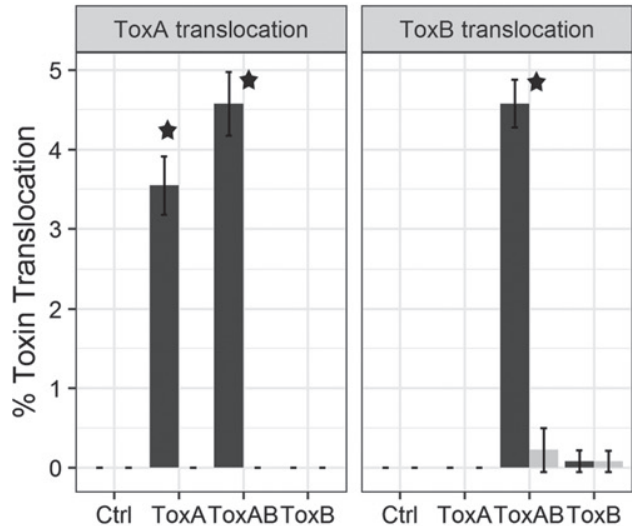

White Onion

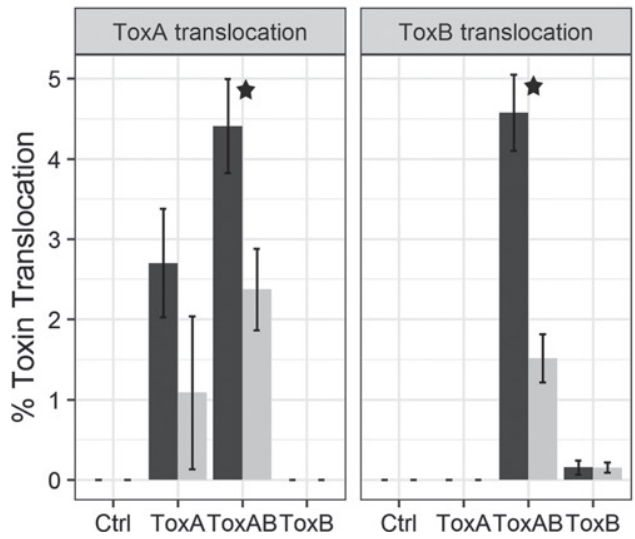

\section{Treatment}

- Food Compound

+ Food Compound
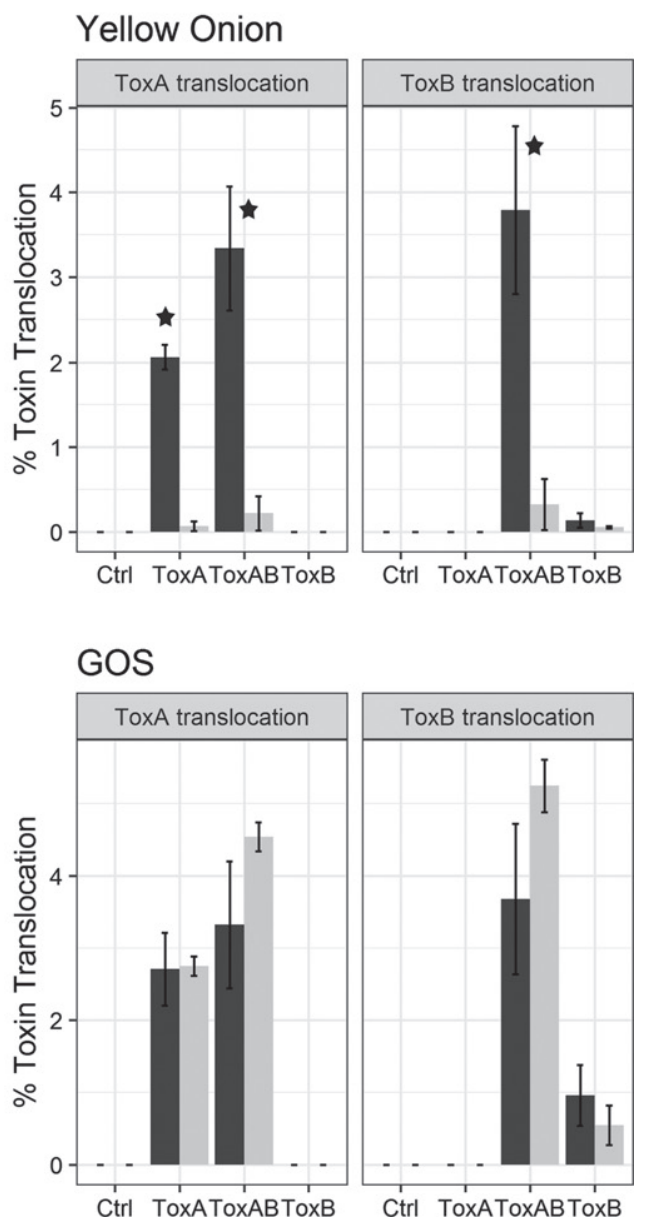

Fig. 6. ToxA and ToxB translocation measured using ELISA. Measurements were made in the basolateral medium of Caco-2 cells with and without exposure of food compounds namely blackcurrant (Ben Finlay), strawberry (Sabrina), yellow onion, white onion and GOS. '*, indicates significant results compared against control. 
significant structural conservation with ubiquitin [51]. They have several isoforms in humans and some of the isoforms are found to be ubiquitously expressed in human organs while others are restricted to few organs. Sumoylation pathway is the post translational modification of some target proteins where the SUMO proteins attach and detach covalently to their targets and thus modify the functions of the respective target genes [52]. Rho GTPases, which are known to be affected by C. difficile toxins [4], can also be regulated by post-translational sumoylation [53]. Furthermore, Rho GTPases are reported to be key regulators of the actin cytoskeleton and can affect cell shape (like rounding of cells) thus influencing cell-cell connection and integrity of cell layer [39]. Also other proteins linked to intestinal integrity, like tight junction proteins and p53 (apoptosis) are reported to be regulated by sumoylation $[54,55]$. So, by regulating RhoGTPase activity, tight junction proteins and apoptosisrelated proteins, sumoylation might have a direct role in intestinal integrity. Sumoylation pathway is also found to be an important target of bacterial infection $[56,57]$ and although it is reported to play a role in bacterial infections in general $[51,57,58]$, no previous study reports its activation by $C$. difficile toxins.

In addition to the Sumoylation pathway, cell and DNA repair pathways, tight junction signaling, and some cytokine activation pathways are significantly perturbed by C. difficile toxins. This has also been mentioned in previous studies [45, 46, 59]. In many of these pathways RhoGTPases are involved. Interestingly, p53 signaling pathway was significantly perturbed on exposure to Tox $\mathrm{AB}$ and not on exposure to toxins individually. This could be due to the synergistic effects of ToxA and ToxB in $C$. difficile infection.

Recently, an in vitro study probing the impact of natural products on $C$. difficile toxins was performed using HT29 and vero cells [60]. Furthermore, many transcriptomics-based analyses have been conducted on Caco-2 cells exposed to different foods and other luminal factors. We have made use of many available transcriptomics dataset and performed an integrative analysis to conceptualize the present experiment. This study is a complimentary work and takes an interdisciplinary approach to identify useful food compounds that mitigate the effects of $C$. difficile toxins. The enhanced context provided by this compendium allowed the prediction of food compounds that might alleviate the effects of CDI. PCA is a common technique for dimensionality reduction [30] and has been used over the years for descriptive and inferential statistics [30, 61]. The PCA plots presented in this work were interpreted on the assumption that a compound, which is most distinct from toxins and toxoids based on transcriptomic effects in Caco-2 cells, might be most counteracting to the cytotoxic effects of toxins. On the other hand, a compound closer to the toxoids is expected to show an effect more similar to that of toxoids, meaning less counteracting or no beneficial effect at all. Food substances chosen based on this assumption proved (by experiments) to have the predicted relative efficiencies (so, blackcurrant - most effective, strawberry and yellow onion - moderately effective and white onion and GOS - least effective). In our study we did not test compounds that were close to toxins, as their interpretation might be more ambiguous, as similar gene expression patterns and close proximity in the PCA plot indicate foods that trigger similar response as the toxins. It could be speculated that these compounds might enhance the effects of toxins by inducing the same pathways as the toxins, such as the induction of apoptotic processes or reduce the effects of the toxins by interfering with the toxin-induced pathways; for instance, pathways associated to defense mechanisms. This might be probed in future experiments. Another potential study would be to focus on the ToxA and ToxB breakdown by selecting specific proteases that block enzyme activity or by providing substrate for the toxins in the hope they will not attack targets on intestinal epithelial cells.

The results of the integrative analysis were followed by experimental characterization of the selected target food compound. In this study we found that berries, such as blackcurrant and strawberries, can have beneficial effects on cytotoxicity induced by $C$. difficile toxins. Berries have been proven to be rich in flavonoids and antioxidants [62], particularly polyphenols and phenolic acids [63, 64] which have been brought in relation with many type of health effects [65]. Lacombe and Wu have provided a detailed review on the effects of berries on different pathogens, including other species of Clostridium and their benefit as antimicrobial substances [62]. Additionally, quercetin is previously shown to be present in blackcurrant, strawberry [66] and yellow onion [67] and has a role in the Sumoylation pathway $[68,69]$. By affecting the sumoylation pathway that is also involved in the cytotoxic effect of $C$. difficile, quercetin might be the chemical compound in blackcurrant, strawberry 
and yellow onion that gives rise to the beneficial effects seen in the $C$. difficile-induced cytotoxicity assays. Follow-up experiments should be performed to identify the mechanism of this beneficial effects. Such sources should further be probed in vivo in animal studies.

Although our study did not show a counteracting effect of GOS on the cytotoxic effects induced by $C$. difficile toxins, this does not exclude the possibility that specific fractions of GOS can still have a beneficial effect. Previously, Sinclair et al. found that specific fractions of GOS (especially DP6; fractionated by cation exchange chromatography) could inhibit the binding of cholera toxins to their effective receptor [70]. This inhibitory effect was not found with unfractionated GOS, as is used in our study.

\section{Conclusion}

This work shows that transcriptomic data can be used to identify beneficial food compounds. Our study, specifically indicates that blackcurrant (Ben Finlay) in particular and strawberry (Sabrina) and yellow onion may help to reduce the cytotoxic effects of $C$. difficile toxins on the small intestinal barrier. This result warrants further studies in animal and human models to prove its effectiveness in vivo.

\section{Acknowledgments}

We would like to thank Friesland Campina, Amersfoort, the Netherlands for providing us with galactooligosaccharides (GOS).

\section{Funding statement}

The project was financially supported by the EU berry project grant application KBBE-366 2010-4 265942 and by the Dutch Ministry of Economic Affairs within the Systems Biology program 'Virtual Gut', KB-17003.02-021.

\section{Author contributions}

PBV, NDW and JM designed the experiments and collected the data. EO, MT performed the wet-lab experiments. PBV, MSD and ES worked on the computational aspects of the paper. PBV and NDW generated the figures. All authors contributed to the discussion of manuscript, writing and proof reading.

\section{Data availability}

Most data generated or analyzed during this study are included in this published article (and its Supplementary Information files). In case of missing data or data under preparation for submission to public repositories, they are also available from the corresponding author on reasonable request.

\section{Conflict of interest}

The authors have no conflict of interest to report. 


\section{Supplementary material}

The Supplementary Material is available in the electronic version of this article: https://dx.doi.org/10.3233/ JBR-200646.

\section{References}

[1] Burke KE, Lamont JT. Clostridium difficile Infection: A Worldwide Disease. Gut Liver. 2014;8:1-6. https://doi.org/10.5009/gnl.2014. 8.1.1.

[2] Leffler DA, Lamont JT. Clostridium difficile Infection. N Engl J Med. 2015;372:1539-48. https://doi.org/10.1056/NEJMra 1403772.

[3] DePestel DD, Aronoff DM. Epidemiology of Clostridium difficile Infection. J Pharm Pract. 2013;26:464-75. https://doi.org/10.1177/ 0897190013499521.

[4] Di Bella S, Ascenzi P, Siarakas S, Petrosillo N, di Masi A. Clostridium difficile Toxins A and B: Insights into Pathogenic Properties and Extraintestinal Effects. Toxins. 2016;8. https://doi.org/10.3390/toxins8050134.

[5] Kasendra M, Barrile R, Leuzzi R, Soriani M. Clostridium difficile Toxins Facilitate Bacterial Colonization by Modulating the Fence and Gate Function of Colonic Epithelium. J Infect Dis. 2014;209:1095-104. https://doi.org/10.1093/infdis/jit617.

[6] Du T, Alfa MJ. Translocation of Clostridium difficile toxin B across polarized Caco-2 cell monolayers is enhanced by toxin A. Can J Infect Dis. 2004;15:83-8.

[7] Navaneethan U, Giannella RA. Thinking beyond the colon-small bowel Involvement in clostridium difficile infection. Gut Pathog. 2009;1:7. https://doi.org/10.1186/1757-4749-1-7.

[8] Freiler JF, Durning SJ, Ender PT. Clostridium difficile Small Bowel Enteritis Occurring after Total Colectomy. Clin Infect Dis. 2001;33:1429-31. https://doi.org/10.1086/322675.

[9] Boland E, Thompson JS. Fulminant Clostridium difficile Enteritis after Proctocolectomy and Ileal Pouch-Anal Anastamosis. Gastroenterol Res Pract. 2008. https://doi.org/10.1155/2008/985658.

[10] Killeen S, Martin ST, Hyland J, O' Connell PR, Winter DC. Clostridium difficile enteritis: A new role for an old foe. The Surgeon. 2014;12:256-62. https://doi.org/10.1016/j.surge.2014.01.008.

[11] Schubl SD, Raymond L, Robitsek RJ, Bagheri F. Isolated Clostridium difficile Small Bowel Enteritis in the Absence of Predisposing Factors. Surg Infect Case Rep. 2016;1:38-40. https://doi.org/10.1089/crsi.2016.0006.

[12] Testore GP, Nardi F, Babudieri S, Giuliano M, Rosa RD, Panichi G. Isolation of Clostridium difficile from human jejunum: identification of a reservoir for disease? J Clin Pathol 1986;39:861-2. https://doi.org/10.1136/jcp.39.8.861.

[13] Butler M, Olson A, Drekonja D, Shaukat A, Schwehr N, Shippee N, et al. Early Diagnosis, Prevention, and Treatment of Clostridium difficile: Update. Rockville (MD): Agency for Healthcare Research and Quality (US); 2016.

[14] Navaneethan U, Venkatesh PG, Shen B. Clostridium difficile infection and inflammatory bowel disease: Understanding the evolving relationship. World J Gastroenterol WJG. 2010;16:4892-904. https://doi.org/10.3748/wjg.v16.i39.4892.

[15] Spigaglia P. Recent advances in the understanding of antibiotic resistance in Clostridium difficile infection. Ther Adv Infect Dis. 2016;3:23-42. https://doi.org/10.1177/2049936115622891.

[16] Zhang L, Ma J, Pan K, Go VLW, Chen J, You W. Efficacy of Cranberry Juice on Helicobacter pylori Infection: a Double-Blind, Randomized Placebo-Controlled Trial. Helicobacter. 2005;10:139-45. https://doi.org/10.1111/j.1523-5378.2005.00301.x.

[17] Vreeburg RA, van Wezel EE, Ocaña-Calahorro F, Mes JJ. Apple extract induces increased epithelial resistance and claudin 4 expression in Caco-2 cells. J Sci Food Agric. 2012;92:439-44. https://doi.org/10.1002/jsfa.4598.

[18] Minekus M, Alminger M, Alvito P, Ballance S, Bohn T, Bourlieu C, et al. A standardised static in vitro digestion method suitable for food - an international consensus. Food Funct. 2014;5:1113-24. https://doi.org/10.1039/C3FO60702J.

[19] Gentleman RC, Carey VJ, Bates DM, Bolstad B, Dettling M, Dudoit S, et al. Bioconductor: open software development for computational biology and bioinformatics. Genome Biol. 2004;5:R80. https://doi.org/10.1186/gb-2004-5-10-r80.

[20] Lin K, Kools H, de Groot PJ, Gavai AK, Basnet RK, Cheng F, et al. MADMAX - Management and analysis database for multiple omics experiments. J Integr Bioinforma. 2011;8:160. https://doi.org/10.2390/biecoll-jib-2011-160.

[21] Bolstad BM, Irizarry RA, Astrand M, Speed TP. A comparison of normalization methods for high density oligonucleotide array data based on variance and bias. Bioinforma Oxf Engl. 2003;19:185-93.

[22] Irizarry RA, Bolstad BM, Collin F, Cope LM, Hobbs B, Speed TP. Summaries of Affymetrix GeneChip probe level data. Nucleic Acids Res. 2003;31:e15. 
[23] Dai M, Wang P, Boyd AD, Kostov G, Athey B, Jones EG, et al. Evolving gene/transcript definitions significantly alter the interpretation of GeneChip data. Nucleic Acids Res. 2005;33:e175-e175. https://doi.org/10.1093/nar/gni179.

[24] Piccolo SR, Withers MR, Francis OE, Bild AH, Johnson WE. Multiplatform single-sample estimates of transcriptional activation. Proc Natl Acad Sci. 2013;110:17778-83. https://doi.org/10.1073/pnas.1305823110.

[25] Venkatasubramanian PB, Toydemir G, Wit N, Saccenti E, Santos VAPM dos, Baarlen P, et al. Use of Microarray Datasets to generate Caco-2-dedicated Networks and to identify Reporter Genes of Specific Pathway Activity. Sci Rep. 2017;7:6778. https://doi.org/10.1038/s41598-017-06355-0.

[26] Gautier L, Cope L, Bolstad BM, Irizarry RA. affy—analysis of Affymetrix GeneChip data at the probe level. Bioinformatics. 2004;20:307-15. https://doi.org/10.1093/bioinformatics/btg405.

[27] Carvalho BS, Irizarry RA. A framework for oligonucleotide microarray preprocessing. Bioinformatics. 2010;26:2363-7. https://doi. org/10.1093/bioinformatics/btq431.

[28] Ritchie ME, Phipson B, Wu D, Hu Y, Law CW, Shi W, et al. limma powers differential expression analyses for RNA-sequencing and microarray studies. Nucleic Acids Res. 2015;43:e47. https://doi.org/10.1093/nar/gkv007.

[29] Phipson B, Lee S, Majewski IJ, Alexander WS, Smyth GK. Robust hyperparameter estimation protects against hypervariable genes and improves power to detect differential expression. Ann Appl Stat. 2016;10:946-63. https://doi.org/10.1214/16-AOAS920.

[30] Jolliffe IT, Cadima J. Principal component analysis: a review and recent developments. Philos Transact A Math Phys Eng Sci. $2016 ; 374$. https://doi.org/10.1098/rsta.2015.0202.

[31] Saccenti E, Hoefsloot HCJ, Smilde AK, Westerhuis JA, Hendriks MMWB. Reflections on univariate and multivariate analysis of metabolomics data. Metabolomics. 2014;10:361-74. https://doi.org/10.1007/s11306-013-0598-6.

[32] Saccenti E, Timmerman ME. Considering Horn's Parallel Analysis from a Random Matrix Theory Point of View. Psychometrika. 2017;82:186-209. https://doi.org/10.1007/s11336-016-9515-z.

[33] Johnstone IM. On the Distribution of the Largest Eigenvalue in Principal Components Analysis. Ann Stat. 2001;29:295-327.

[34] Guo C, Wei Q, Su Y, Dong Z. SUMOylation occurs in acute kidney injury and plays a cytoprotective role. Biochim Biophys Acta. 2015;1852:482-9. https://doi.org/10.1016/j.bbadis.2014.12.013.

[35] He J, Cheng J, Wang T. SUMOylation-Mediated Response to Mitochondrial Stress. Int J Mol Sci. 2020;21:5657. https://doi.org/ 10.3390/ijms21165657.

[36] Lerm M, Schmidt G, Aktories K. Bacterial protein toxins targeting Rho GTPases. FEMS Microbiol Lett. 2000;188:1-6. https://doi.org/10.1111/j.1574-6968.2000.tb09159.x.

[37] Voth DE, Ballard JD. Clostridium difficile Toxins: Mechanism of Action and Role in Disease. Clin Microbiol Rev. 2005;18:247-63. https://doi.org/10.1128/CMR.18.2.247-263.2005.

[38] Gloushankova N, Ossovskaya V, Vasiliev J, Chumakov P, Kopnin B. Changes in p53 expression can modify cell shape of rastransformed fibroblasts and epitheliocytes. Oncogene 1997;15:2985-9. https://doi.org/10.1038/sj.onc.1201483.

[39] Hall A. Rho GTPases and the actin cytoskeleton. Science 1998;279:509-14. https://doi.org/10.1126/science.279.5350.509.

[40] Kuehne SA, Cartman ST, Heap JT, Kelly ML, Cockayne A, Minton NP. The role of toxin A and toxin B in Clostridium difficile infection. Nature. 2010;467:711-3. https://doi.org/10.1038/nature09397.

[41] Mitchell TJ, Ketley JM, Haslam SC, Stephen J, Burdon DW, Candy DC, et al. Effect of toxin A and B of Clostridium difficile on rabbit ileum and colon. Gut. 1986;27:78-85. https://doi.org/10.1136/gut.27.1.78.

[42] Hecht G, Pothoulakis C, LaMont JT, Madara JL. Clostridium difficile toxin A perturbs cytoskeletal structure and tight junction permeability of cultured human intestinal epithelial monolayers. J Clin Invest. 1988;82:1516-24.

[43] Riegler M, Sedivy R, Pothoulakis C, Hamilton G, Zacherl J, Bischof G, et al. Clostridium difficile toxin B is more potent than toxin A in damaging human colonic epithelium in vitro. J Clin Invest. 1995;95:2004-11.

[44] Buckley AM, Spencer J, Maclellan LM, Candlish D, Irvine JJ, Douce GR. Susceptibility of Hamsters to Clostridium difficile Isolates of Differing Toxinotype. PLOS ONE. 2013;8:e64121. https://doi.org/10.1371/journal.pone.0064121.

[45] D'Auria KM, Donato GM, Gray MC, Kolling GL, Warren CA, Cave LM, et al. Systems analysis of the transcriptional response of human ileocecal epithelial cells to Clostridium difficile toxins and effects on cell cycle control. BMC Syst Biol. $2012 ; 6: 2$. https://doi.org/10.1186/1752-0509-6-2.

[46] D'Auria KM, Kolling GL, Donato GM, Warren CA, Gray MC, Hewlett EL, et al. In Vivo Physiological and Transcriptional Profiling Reveals Host Responses to Clostridium difficile Toxin A and Toxin B. Infect Immun. 2013;81:3814-24. https://doi.org/10.1128/IAI.00869-13.

[47] Gerhard R, Tatge H, Genth H, Thum T, Borlak J, Fritz G, et al. Clostridium difficile Toxin A Induces Expression of the Stress-induced Early Gene Product RhoB. J Biol Chem. 2005;280:1499-505. https://doi.org/10.1074/jbc.M406014200.

[48] Janvilisri T, Scaria J, Chang Y-F. Transcriptional profiling of Clostridium difficile and Caco-2 cells during infection. J Infect Dis. 2010;202:282-90. https://doi.org/10.1086/653484. 
[49] Berahovich RD, Miao Z, Wang Y, Premack B, Howard MC, Schall TJ. Proteolytic Activation of Alternative CCR1 Ligands in Inflammation. J Immunol. 2005;174:7341-51. https://doi.org/10.4049/jimmunol.174.11.7341.

[50] Shen L, Chen C, Wei X, Li X, Luo G, Zhang J, et al. Overexpression of ankyrin repeat domain 1 enhances cardiomyocyte apoptosis by promoting 553 activation and mitochondrial dysfunction in rodents. Clin Sci. 2015;128:665-78. https://doi.org/10.1042/CS20140586.

[51] Srikanth CV, Verma S. Sumoylation as an Integral Mechanism in Bacterial Infection and Disease Progression. 2017:389-408. https://doi.org/10.1007/978-3-319-50044-7_22.

[52] Hay RT. SUMO. Mol Cell. 2005;18:1-12. https://doi.org/10.1016/j.molcel.2005.03.012.

[53] Haga RB, Ridley AJ. Rho GTPases: Regulation and roles in cancer cell biology. Small GTPases. 2016;7:207-21. https://doi.org/ $10.1080 / 21541248.2016 .1232583$.

[54] Van Itallie CM, Mitic LL, Anderson JM. SUMOylation of claudin-2. Ann N Y Acad Sci. 2012;1258:60-4. https://doi.org/ 10.1111/j.1749-6632.2012.06541.x.

[55] Marcos-Villar L, Pérez-Girón J, Vilas J, Soto A, Cruz-Hererra C de la, Lang V, et al. SUMOylation of p53 mediates interferon activities. Cell Cycle. 2013;12:2809-16. https://doi.org/10.4161/cc.25868.

[56] David R. Bacterial pathogenesis: Targeting SUMO. Nat Rev Microbiol. 2010;8:386-386. https://doi.org/10.1038/nrmicro2371.

[57] Ribet D, Cossart P. SUMOylation and bacterial pathogens. Virulence. 2010;1:532-4.

[58] Fritah S, Lhocine N, Golebiowski F, Mounier J, Andrieux A, Jouvion G, et al. Sumoylation controls host anti-bacterial response to the gut invasive pathogen Shigella flexneri. EMBO Rep. 2014;15:965-72. https://doi.org/10.15252/embr.201338386.

[59] Nusrat A, Eichel-Streiber C von, Turner JR, Verkade P, Madara JL, Parkos CA. Clostridium difficile Toxins Disrupt Epithelial Barrier Function by Altering Membrane Microdomain Localization of Tight Junction Proteins. Infect Immun. 2001;69:1329-36. https://doi.org/10.1128/IAI.69.3.1329-1336.2001.

[60] Roshan N, Riley TV, Knight DR, Hammer KA. Effect of natural products on the production and activity of Clostridium difficile toxins in vitro. Sci Rep. 2018;8:1-9. https://doi.org/10.1038/s41598-018-33954-2.

[61] Kaya IE, PehlivanlıAÇ, Sekizkardeş EG, Ibrikci T. PCA based clustering for brain tumor segmentation of T1w MRI images. Comput Methods Programs Biomed. 2017;140:19-28. https://doi.org/10.1016/j.cmpb.2016.11.011.

[62] Lacombe A, Wu VCH. The potential of berries to serve as selective inhibitors of pathogens and promoters of beneficial microorganisms. Food Qual Saf. 2017;1:3-12. https://doi.org/10.1093/fqsafe/fyx001.

[63] Brown EM, McDougall GJ, Stewart D, Pereira-Caro G, González-Barrio R, Allsopp P, et al. Persistence of Anticancer Activity in Berry Extracts after Simulated Gastrointestinal Digestion and Colonic Fermentation. PLOS ONE. 2012;7:e49740. https://doi.org/10.1371/journal.pone.0049740.

[64] Oszmiański J, Nowicka P, Teleszko M, Wojdyło A, Cebulak T, Oklejewicz K. Analysis of Phenolic Compounds and Antioxidant Activity in Wild Blackberry Fruits. Int J Mol Sci. 2015;16:14540-53. https://doi.org/10.3390/ijms160714540.

[65] Boeing H, Bechthold A, Bub A, Ellinger S, Haller D, Kroke A, et al. Critical review: vegetables and fruit in the prevention of chronic diseases. Eur J Nutr. 2012;51:637-63. https://doi.org/10.1007/s00394-012-0380-y.

[66] Sari H. Häkkinen †, Sirpa O. Kärenlampi $\S$, I. Marina Heinonen \|, Hannu M. Mykkänen †and, A. Riitta Törrönen †. Content of the Flavonols Quercetin, Myricetin, and Kaempferol in 25 Edible Berries 1999. https://doi.org/10.1021/jf9811065.

[67] Griffiths G, Trueman L, Crowther T, Thomas B, Smith B. Onions-A global benefit to health. Phytother Res. 2002;16:603-15. https://doi.org/10.1002/ptr.1222.

[68] Lee Y, Bernstock JD, Nagaraja N, Ko B, Hallenbeck JM. Global SUMOylation facilitates the multimodal neuroprotection afforded by quercetin against the deleterious effects of oxygen/glucose deprivation and the restoration of oxygen/glucose. J Neurochem. 2016;138:101-16. https://doi.org/10.1111/jnc.13643.

[69] Velazhahan V, Glaza P, Herrera AI, Prakash O, Zolkiewski M, Geisbrecht BV, et al. Dietary flavonoid fisetin binds human SUMO1 and blocks sumoylation of p53. PLOS ONE. 2020;15:e234468. https://doi.org/10.1371/journal.pone.0234468.

[70] Sinclair HR, de Slegte J, Gibson GR, Rastall RA. Galactooligosaccharides (GOS) Inhibit Vibrio cholerae Toxin Binding to Its GM1 Receptor. J Agric Food Chem. 2009;57:3113-9. https://doi.org/10.1021/jf8034786. 